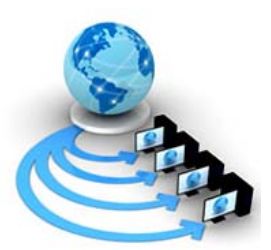

Volume 8, No. 9, November-December 2017

International Journal of Advanced Research in Computer Science

RESEARCH PAPER

\title{
RESEARCH PAPER ON MINIATURIZED CROSS SQUARE ANTENNA USING FRACTAL GEOMETRY FOR WIRELESS APPLICATIONS
}

\author{
Ramandeep Kaur \\ M.Tech: Electronics and Communication Engineering \\ Sant Baba Bhag Singh University \\ Jalandhar, India
}

\author{
Mandeep kaur \\ HOD:Electronics and Communication Engineering \\ Sant Baba Bhag Singh University \\ Jalandhar, India
}

\begin{abstract}
In this paper develop and analyze the novel fractal geometry for microstrip patch antenna. The antenna develops, designed and analyzes using HFSS (High Frequency Structure Simulator). This antenna uses the material FR4-epoxy substrate with 4.4 dielectric constant and 1.5676 substrate thicknesses. The material used for patch and ground plane is copper and coaxial feed is used in this design. The maximum return loss of this design is $-42.32 \mathrm{db}$ at $14.3 \mathrm{GHz}$ using substrate size $38 \mathrm{x} 38 \mathrm{~mm}$. This antenna design is applicable for various applications.
\end{abstract}

Keywords: fractal antenna, HFSS, return loss, VSWR, gain

\section{INTRODUCTION}

In the present day the modern communication system is required antenna with advance features like wider bandwidths. Multi bands, smaller size, high gain low profile antenna. This has initiated research in various directions, one of which is fractal shaped antenna. In resent year various geometries have been introduced for antenna applications with different dimensions and varying degree of success for improves antenna characteristics. Some geometry designed for reduce antenna size and other for multiband applications.

In 1970s Munson and Howell develop practical microstrip antennas [1]. With the evolution of embedded technology the mobile devices became more capable to provide different services like data services, GPS (Global Positioning System), Financial and banking services, blue-tooth, Wi-Fi etc. including the voice services [2]. For this type of advance system it requires an antenna which can provide maximum operating frequency on broad spectrum of band- width because good antenna will improve the performance of system.

The term fractal was discovered by the French mathematician B.B. Mandelbrot during 1970's after his pioneering research on several naturally occurring irregular and fragmented geometries not containerlend within the realms of conventional Euclidian geometry [3]. The word fractal is derived from Latin Greek word fractus which means irregular fragmented or shapes. Fractal antennas are widely used because its self similarity and space filling property reduce the antenna size and make it light weight antenna. The self similar property provides multiband behavior, because using this property, the portion of geometry which has same shape repeat at reduces scale [4]. And the space filling property used to reduce the size of antenna. Fractal antenna is based on iterations means it repeating itself by reducing the size. The iteration function system is collection of self alien transformation [5]. Fractal geometries have been applied to micro strip antenna design to make multiband and broadband antennas. In addition, fractal geometries have been used to miniaturize the size of the antennas. There are two categories of fractal geometry such ad deterministic and non deterministic [6].

\section{ANTENNA DESIGN PROCEDURE}

The necessary parameters used in designing rectangular microstrip patch antenna are frequency of operation and resonant frequency where as $3.4 \mathrm{GHz}$ is taken for proposed antenna design. In this antenna design the FR4-epoxy glass substrate is used with dielectric constant 4.4 and substrate thickness is 1.5676 . The high value of the dielectric constant of substrate can be used to reduce the dimension of antenna. A square feed patch of length $26 \mathrm{~mm}$ and breadth $26 \mathrm{~mm}$ is considered with finite length $38 \mathrm{~mm}$ and breadth $38 \mathrm{~mm}$ of ground plane. The coaxial feed is used to excite square patch. The dimensions of the proposed antenna are shown in table 1.

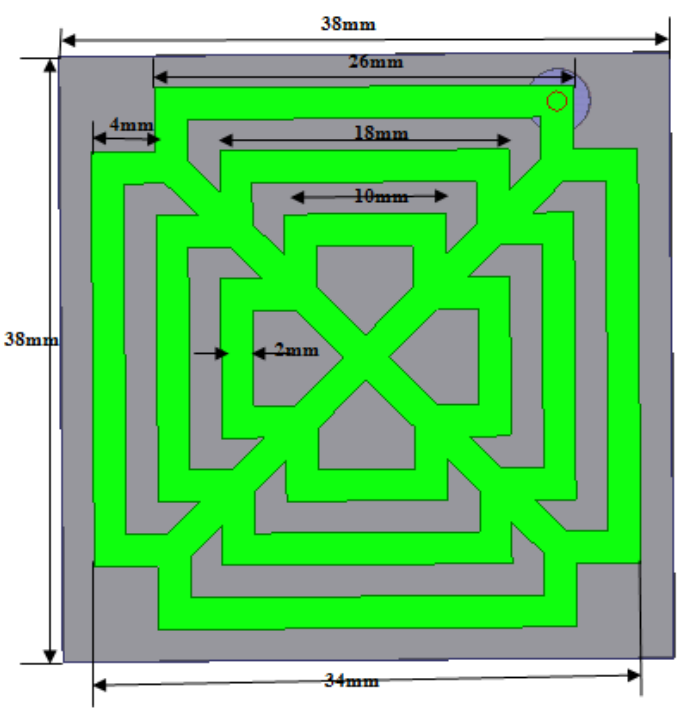

Figure1. Square Cross Fractal Antenna 
Table 1 Dimension of Proposed Antenna

\begin{tabular}{|c|c|c|c|}
\hline $\begin{array}{c}\text { S. } \\
\text { No. }\end{array}$ & Parametr & Description & Values \\
\hline 1 & Ws & $\begin{array}{c}\text { Width of substrate } \\
\text { \& ground plane }\end{array}$ & $38 \mathrm{~mm}$ \\
\hline 2 & Ls & $\begin{array}{c}\text { Length of substrate } \\
\text { \& ground plane }\end{array}$ & $38 \mathrm{~mm}$ \\
\hline 3 & Hs & Height of patch & $\begin{array}{c}1.5676 \mathrm{~m} \\
\mathrm{~m}\end{array}$ \\
\hline 5 & Wp & Width of patch & $34 \mathrm{~mm}$ \\
\hline 6 & Lp & Length of patch & $34 \mathrm{~mm}$ \\
\hline
\end{tabular}

The cross slot as shown in figure 2 is further modified to make a square cross structure of patch. The $2^{\text {nd }}$ and $3^{\text {rd }}$ iterations are shown in figure 3 and 4 respectively. These iterations are designed to analyze the performance of designed antenna up to the $3^{\text {rd }}$ iteration. The modification in the patch of antenna is done by using software HFSS, and different parameters of all the iteration has been observed and discussed in this paper.

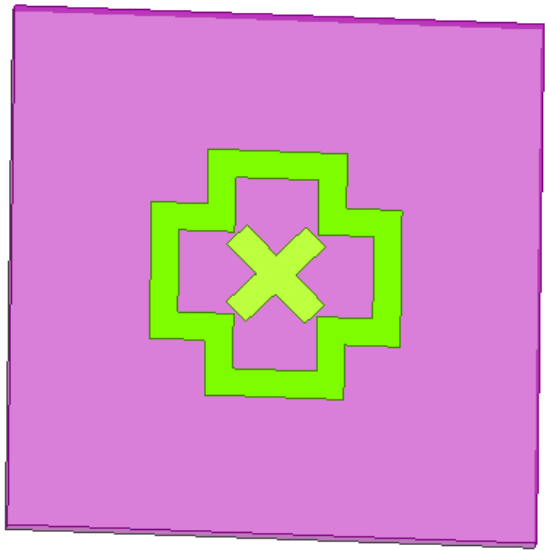

Figure 2. Square cross antenna- First iteration

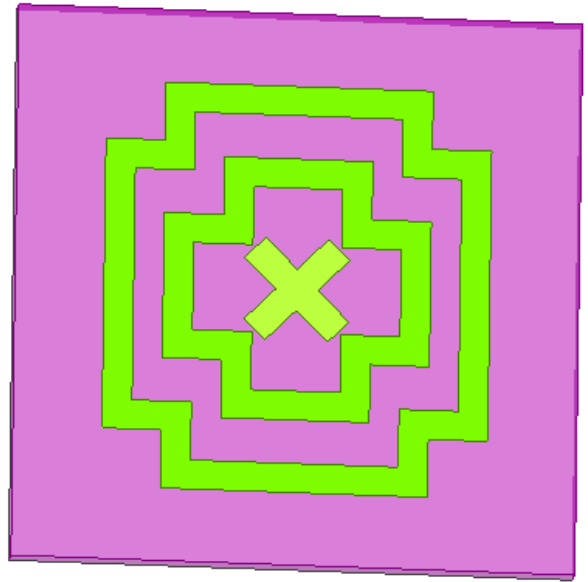

Figure 3. Square cross antenna- Second iteration

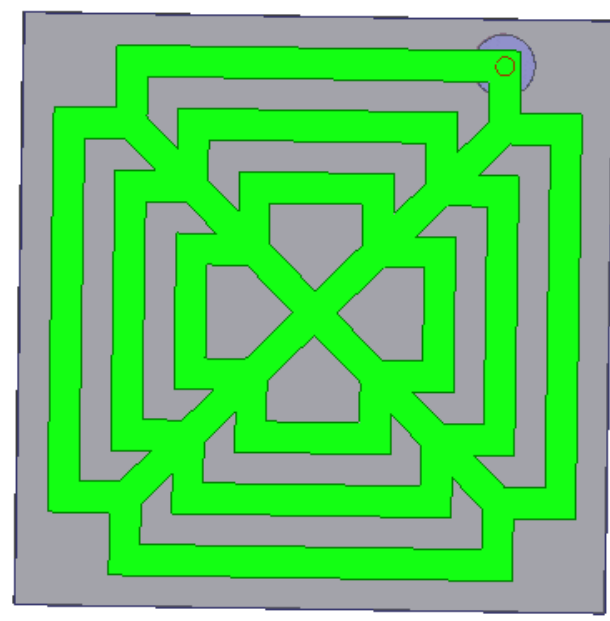

Figure 4. Square cross antenna- Third iteration

\section{SIMULATION AND RESULT DISCUSSION}

\section{A. Return loss}

Return loss is defined as ratio of power reflected from a device under test to power incident to that device. It means loss of power in signal reflected by discontinuity in transmission line is called return loss [7]. The figure 5 shows the return loss characteristics of designed antenna. Table 2 and shows the parametric explanation of return loss graph. From the figure and table of return loss, it is observed from design that by connecting the internal loops of antenna increases the bandwidth of antenna especially at ISM band. Both $2.4 \mathrm{GHz}$ and $5.6 \mathrm{GHz}$ band of ISM will cover and provided the sufficient bandwidth. From this antenna design there are seven different frequencies are observed with their respective return loss. It is quite obvious from figure 5 that antenna resonant at seven different frequencies such as $3 \mathrm{GHz}, 4.9 \mathrm{GHz}, 5.2 \mathrm{GHz}$, 7.2GHz, 9.7GHz, $10.8 \mathrm{GHz}, 14.6 \mathrm{GHz}$ and their respective return loss are $-36.5 \mathrm{db},-23.62 \mathrm{db},-25.04 \mathrm{db},-27.86 \mathrm{gb}$, 17.42db, -42.32db, -37.06db.

Table 2. Return Loss Graph Analysis

\begin{tabular}{|c|c|c|}
\hline Sr. No & $\begin{array}{c}\text { Frequency (in } \\
\mathrm{GHz} \text { ) }\end{array}$ & $\begin{array}{c}\text { Return loss } \\
\text { (in db) }\end{array}$ \\
\hline 1 & $3.0 \mathrm{GHz}$ & -36.5 \\
\hline 2 & $4.9 \mathrm{GHz}$ & -23.62 \\
\hline 3 & $5.2 \mathrm{GHz}$ & -25.04 \\
\hline 4 & $7.2 \mathrm{GHz}$ & -27.86 \\
\hline 5 & $9.7 \mathrm{GHz}$ & -17.42 \\
\hline 6 & $10.8 \mathrm{GHz}$ & -42.34 \\
\hline 7 & $14.6 \mathrm{GHz}$ & -37.06 \\
\hline
\end{tabular}




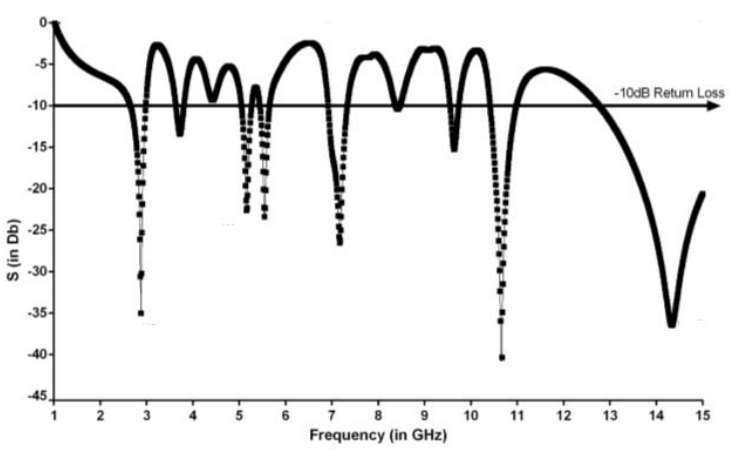

Figure 5. Return loss

\section{B. VSWR}

It is a real number ranging from one to infinity. It is defined as ratio of maximum voltage to minimum voltage. It is related to return loss; it is inversely proportional to return loss [8]. VSWR $=1$ implies that it's a matched load which is an ideal case. VSWR of 1.5 is consider excellent, while values in the range of 1.5 to 2.0 is consider as good and values higher than 2.0 never accepted [9]. At all frequencies (3.4 GHz, $11 \mathrm{GHz}$ and $14.3 \mathrm{GHz}$ ) value of VSWR is approximately 1 , which is best suited for antenna design. The results graph shown in figure 6 .

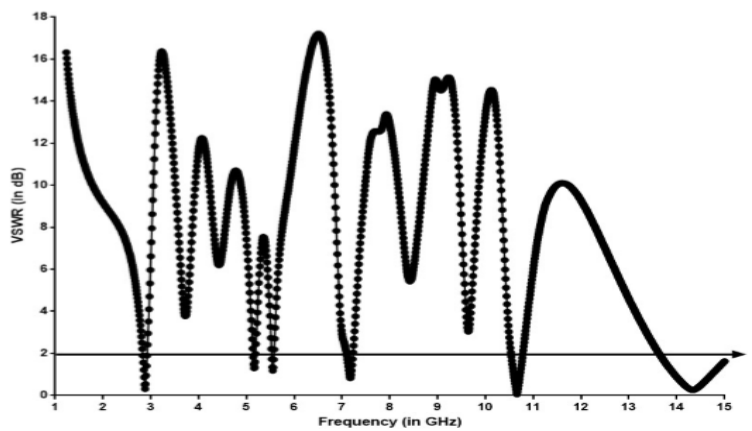

Figure 6. VSWR

\section{Gain}

Gain is defined as ratio of intensity of antenna in direction of peak amplitude relative to intensity of isotropic antenna in that direction [10]. The gain of antenna is represented in figure 7 to 12 at different resonance frequencies in 3D radiation patterns. All figures represents that the gain having positive value at phi $=0$ and more than $3 \mathrm{~dB}$ which is good for efficient energy transfer.
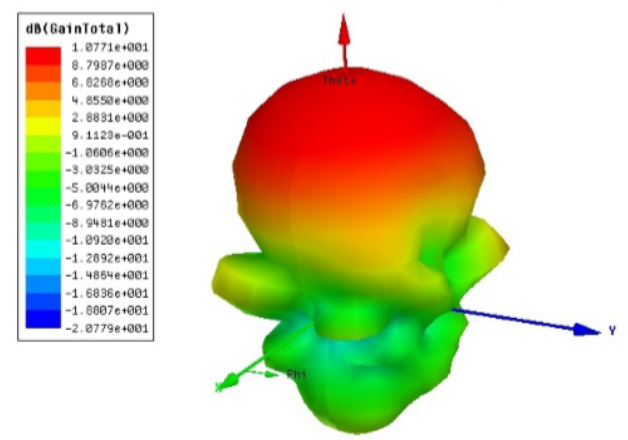

Figure 7. Gain of antenna at $3.0 \mathrm{GHz}$

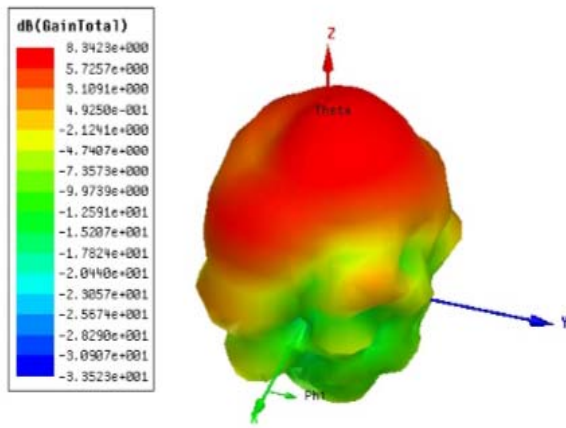

Figure 8. Gain of antenna at $5.2 \mathrm{GHz}$

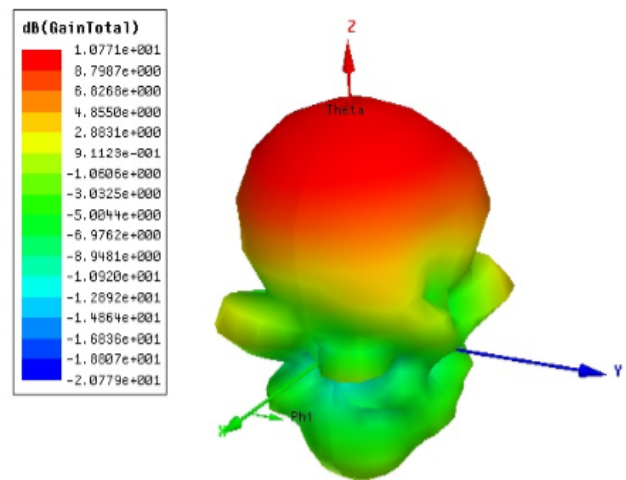

Figure 9. Gain of antenna at 7.2
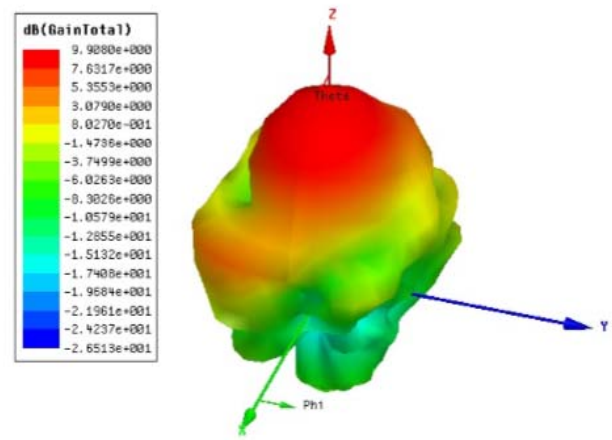

Figure 10. Gain of antenna at $9.7 \mathrm{GHz}$
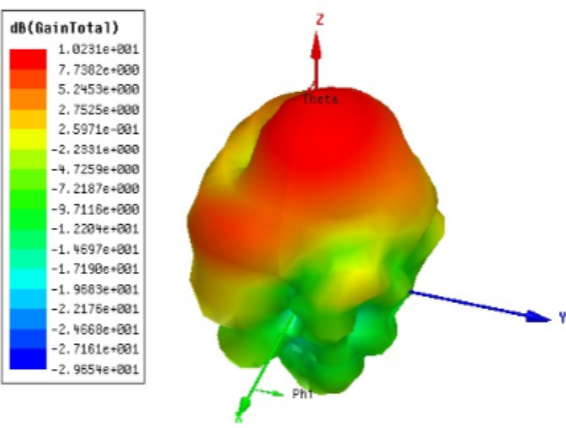

Figure 11. Gain of antenna at $10.8 \mathrm{GHz}$ 


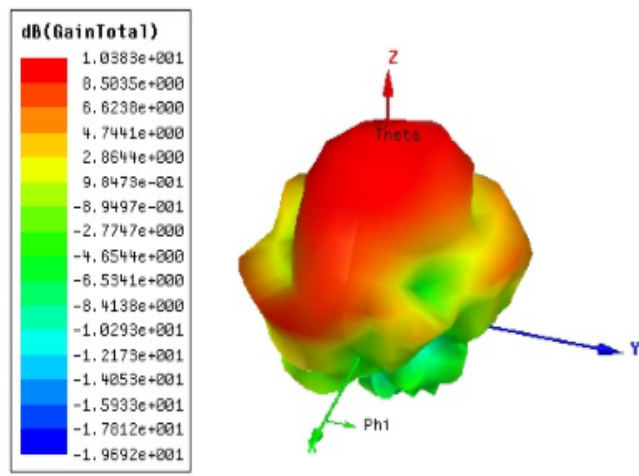

Figure 12 Gain of antenna at $14.3 \mathrm{GHz}$

\section{CONCLUSION}

The result show that the proposed antenna design; square cross fractal antenna with third iteration is better in performance in term of return loss, voltage standing wave ratio, gain and bandwidth compared to conventional patch antenna. The simulation and measured result show good agreement. The radiation patterns at all resonance frequencies show good gain (having positive values). Due to the fractal property of repeating the geometry again and again with different scales produces the multi-band resonance frequencies. The main achievement in this design is to get resonance frequencies in ISM band and higher order frequencies in this size of antenna i.e. $(38 \times 38 \mathrm{~mm} 2)$. We conclude that the final design of antenna using prefrontal geometry is capable of operating at ISM band with large bandwidth, $7 \mathrm{GHz}, 8.7 \mathrm{GHz}, 9.7 \mathrm{GHz}, 10.8 \mathrm{GHz}, 13.4 \mathrm{GHz}$ and $15.6 \mathrm{GHz}$.

\section{FUTURE SCOPE}

This work will provide the way for future work on some different fractal geometries than congenital geometries such as
Koch, Sierpinski, minkowaski etc. This geometry can also study on different dimensions of thickness. In future and feeding techniques and different material types can also affect the performance of antenna. By using other optimization techniques we can increase the bandwidth and gain of antenna at multiple frequencies and it will also give the better results in future.

\section{REFERENCES}

[1] J.Q.Howell.“MicrostripAntennas”.In:IEEETrans.AntennasPropa gation(1975)

[2] I. J. Bah and P. Bhartia. Microstrip Antennas. "MA: Artech House," 1980.

[3] B.B. Mandelbrot. "The Fractal Geometry of Nature. W.H. Frreman," 1983.

[4] Ankita Tiwari, Dr. Munish Rattan, Isha Gupta, "Fractal Antenna Design Geometries and Its Applications," International Journal Of Engineering And Computer Science, Volume - 3 Issue -9 September, 2014, pp 8270-8275.

[5] J.R. James and P. S. Hall. "Handbook of Microstrip Antennas," London: Peter Peregrinus Ltd. 1989

[6] A. Azari, J. Rowhani, "Ultra widebnad fractal microstrip antenna design," volume 2, 7-12, 2008, pp 7-12

[7] Abolfazl azari, "A new fractal antena for super wideband applications,” july 5-8 2010, pp 885-888.

[8] Deepti Singh, sukhwinder kumar, "Stimulation of New Fractal Antenna with Improved Return Loss at Various Frequencies for Ultra Wide Band Applications," International Journal of Advanced Research in Computer and Communication Engineering Vol. 4, Issue 6, June 2015, pp 261-264.

[9] Karandeep Singh Sekhon, Navdeep Singh Sidhu, Loveleen Cheema, "Design and Analysis of Triangular-Circular Fractal Antenna for UWB Applications," International Research Journal of Engineering and Technology Volume: 02 Issue: 02 | May2015, pp 874-878.

[10] Ravkant Sharma, Sauravh Kohli, "Microstrip Sierpinski Fractal Antenna for Wireless Application," International Journal of Advanced Research inComputer Science and Software Engineering. Volume 5, Issue 5,May2015, ISSN: 2277 128X, pp 217-223. 